\title{
EDUCAÇÃO PROFISSIONAL EM UMA PERSPECTIVA INTERNACIONAL COM PARADA E SUAS REPERCUSSÕES NO BRASIL
}

\author{
Olgamir Francisco de Carvalho* \\ Bernardo Kipnis**
}

\section{Resumo}

Este artigo tem por objetivo trazer alguns elementos como contribuição ao debate sobre a educação profissional e tecnológica no Brasil, tendo por base a reflexão, em uma visão internacional comparada, sobre as experiências de alguns países que passaram por um processo de reforma dos seus sistemas. Nesse sentido, busca-se explicitar seu contexto, discutir seus principais conceitos embasadores, identificar seus elementos centrais e observar suas repercussões no Brasil. Os casos da Austrália, Canadá, Coreia do Sul e Portugal são trazidos para iluminar o debate. Julga-se que os elementos analisados possam servir de contribuição ao debate do tema hoje, cotejando as políticas públicas estudadas com aquelas referentes à realidade brasileira.

Palavras-chave: Formação profissional. Educação comparada. Reforma da educação profissional e tecnológica.

\section{Introdução}

Esse artigo se propõe a captar, inicialmente, como a reforma educacional, especificamente na educação profissional e tecnológica, vem sendo construída e aplicada em diferentes contextos internacionais. Trata-se de um momento em que as inter-relações entre diferentes países foram potencializadas pela

* Doutora em Educação pela Universidade Estadual de Campinas, Brasil (1999). Professora Adjunta 3 da Universidade de Brasília (UnB). Coordenadora do Núcleo de Estudos e Pesquisas em Educação e Trabalho, da Faculdade de Educação da UnB (olgamirc@unb.br).

** Ph.D. em Educação pela University of London, Inglaterra (1986), com Pós-Doutoramento na University of California, EUA (1998). Professor da Universidade de Brasília (UnB). Pesquisador do Núcleo de Estudos e Pesquisas em Educação e Trabalho, da Faculdade de Educação da UnB (kipnis@unb.br). 
revolução nas tecnologias de informação e comunicação (TIC), a qual permitiu uma expansão do processo de globalização de forma sem precedentes, atingindo não somente o setor econômico, mas atuando também nas esferas da educação e da cultura.

Os casos da Austrália, Canadá, Coreia do Sul e Portugal são trazidos para iluminar o debate. Julga-se que os elementos analisados possam servir de contribuição, cotejando as políticas públicas estudadas com aquelas referentes à realidade brasileira.

O estudo é produto de pesquisa realizada para a Unidade de Tendências e Prospecção (UNITEP SENAI-DN) e objetivou identificar mudanças na oferta de educação profissional em países selecionados, para setores industriais determinados (máquinas e equipamentos, telecomunicações e eletrônica, têxtil, petroquímica, couro e calçados).

No âmbito deste artigo, os termos educação profissional e formação profissional são compreendidos como conceitos equivalentes, ou seja, a formação profissional associada à escolaridade formal.

O artigo está estruturado em mais quatro seções: a primeira discute o contexto das reformas; a segunda resgata os principais conceitos balizadores das reformas; a terceira, descreve suas linhas norteadoras e, na última seção, fazse o cotejamento com a realidade brasileira.

\section{Globalização, Estado e Políticas Públicas: o contexto das reformas}

Para analisar o contexto no qual se inserem as reformas assinaladas, fazse necessário entender a política pública na perspectiva da globalização, em especial suas implicações para a formação do trabalhador.

Quando falamos de políticas públicas, na atualidade, entendemos um contexto diferenciado daquele que se esboçou no pós-guerra e que foi denominado de paradigma fordista de desenvolvimento. Centrado na produção industrial, aquele momento representou um grande compromisso entre capital e trabalho, mediado pelo Estado, para a distribuição, entre os trabalhadores, dos ganhos de produtividade alcançados. Já na década de 1970, esse modelo começou a apresentar sinais de esgotamento, aprofundado na década de 1980, principalmente em função das inovações tecnológicas surgidas, que acabaram revolucionando as noções de tempo e espaço geográfico. Novas exigências implicaram mudanças na organização econômica e política em nível nacional e no estabelecimento de uma nova ordem econômica internacional.

No campo educacional, presenciamos diversas tentativas de incorporação das novas tecnologias, principalmente da informática, dentro da idéia de long life learning, o aprendizado ao longo da vida, no sentido de que, para a realidade 
presente e para o seu futuro, a educação deve ser continuada, tornando fluido o limite entre escola e trabalho, em termos de tempo e espaço. Na sociedade denominada do conhecimento, a gestão da informação de forma autônoma torna-se primordial e passa a exigir meios diferenciados que facilitem e democratizem o aprendizado. A ideia da educação a distância mediada pelas novas tecnologias adquire força, na medida em que representa uma forte contribuição para essa possibilidade, permitindo a elevação do nível de escolarização e a implementação de uma educação continuada em diferentes espaços educacionais.

Lipietz (1992) observa duas características básicas desse paradigma: a adoção dos princípios tayloristas de administração, racionalizando a produção a partir da separação entre blue collars e white collars, ou seja, o grupo pensante e o grupo operante, dentro de cada empresa, e a mecanização da produção com a elevação da produtividade e do volume de bens de capital por trabalhador. Passa-se a um processo industrial do trabalho de produção de massa para um consumo também de massa.

A proposta da social-democracia, baseada na solução do welfare state, representou um grande compromisso entre empregadores e sindicatos para a melhor redistribuição dos ganhos de produtividade ocorridos, levando a um aumento nos salários reais e à estabilidade nos lucros, com pleno emprego e uso intensivo da capacidade das firmas.

Do ponto de vista da relação do Estado com a economia, montou-se uma legislação social com o estabelecimento do salário mínimo e dos acordos coletivos, bem como um Estado de Bem-estar, com um seguro social capaz de garantir os trabalhadores enquanto consumidores, sustentando, assim, a demanda social agregada associada aos gastos do Estado. Ressalta-se o fato de que esse compromisso foi conseguido a partir da pressão dos trabalhadores organizados em sindicatos, cujo papel naquele momento foi central para o desenvolvimento do modelo.

Esse grande compromisso começa a apresentar uma situação de crise na medida em que os ganhos de produtividade começam a cair sem, no entanto, serem acompanhados por uma redução nos salários e no custo do capital fixo, gerando uma queda nos lucros.

Dupas (1999) aponta para dois movimentos do capitalismo resultantes da crise do paradigma fordista. Por um lado, a revolução nas tecnologias de informação e comunicação, de meados dos anos 1970, repercutiu nas estratégias de produção e distribuição das empresas e no mercado financeiro internacional. De acordo com a possibilidade de rápido deslocamento e comunicação, o capital adquiriu a mobilidade requerida pela globalização da produção, gerando simultaneamente um movimento de concentração, com 
a criação de "gigantes" mundiais, associado, no entanto, a uma onda de fragmentação, observada por meio de terceirizações, franquias e informalização do trabalho.

Por outro lado, o segundo movimento associa-se ao conflito entre inclusão versus exclusão no processo produtivo e de consumo, gerando, de um lado, um desemprego estrutural crescente e, de outro, a necessidade da incorporação de novos mercados pela queda nos preços dos produtos. A consequência do estabelecimento de um modelo não mais industrial, e sim de serviços, pode ser observada com o fracionamento da cadeia produtiva e com o impacto na organização dos trabalhadores. A constituição de sindicatos, resultantes da organização taylorista do trabalho com mão de obra intensiva, na busca de elevação do padrão de vida em uma sociedade de consumo, começa a sofrer um declínio em razão desse novo padrão de acumulação, mais automatizado e fragmentado. Essa nova rearticulação das empresas e o aumento proporcional de trabalhadores white collars, com uma organização mais flexível e menos hierárquica, leva a uma quebra na isonomia salarial, base de sustentação das reivindicações.

Essa perspectiva globalizada de acumulação capitalista traz implicações em relação ao papel do Estado nesse processo. A visão keynesiana do Estado, como sustentador da demanda social, apresenta os seus limites evidenciados por sua crise fiscal, entrando em um processo de endividamento, já incapaz de sustentar o grande compromisso fordista assumido. A globalização, que reduziu a autonomia dos Estados para formular e implementar políticas, e a sua crise fiscal tornam fundamental uma redefinição do seu papel.

Esse é o contexto mais geral no qual as reformas na educação profissional e tecnológica devem ser compreendidas. A nova perspectiva que o trabalho, em sua relação com a educação e a produção, assume nesse novo cenário configura a perspectiva de formação de jovens e adultos que buscam sua inserção no contexto de um capitalismo flexível, globalizado e conectado pela tecnologia da informação e comunicação. Respostas, ou modelos criados, para a reforma da educação profissional e tecnológica, encontrados em distintos países e realidades apontam para convergências e especificidades, cuja compreensão pode ajudar no estabelecimento de políticas públicas no Brasil.

\section{Principais elementos conceituais para compreender as reformas}

Esta seção discute alguns conceitos essenciais para a compreensão das concepções subjacentes às reformas em análise, dentre eles os conceitos de competência e empregabilidade, centrais ao debate, tanto na experiência brasileira quanto nas experiências internacionais pesquisadas. Discute ainda o 
denominado paradigma da educação ao longo da vida e suas implicações para o processo ensino-aprendizagem e a formação do trabalhador.

É indiscutível que a transição do paradigma taylorista / fordista para o novo paradigma técnico econômico, fundado na flexibilização, traz como consequência uma nova concepção de formação profissional. O papel cada vez mais complexo da formação profissional enquanto agente de socialização dos jovens e enquanto meio de proporcionar a estes, e aos trabalhadores em geral, as capacidades profissionais e o conhecimento exigidos pelo setor produtivo coloca na ordem do dia o novo "paradigma" da aprendizagem ao longo da vida.

Para esse paradigma, a formação profissional tem a função de desenvolver a flexibilidade e a mobilidade através da aquisição de capacidades transmissíveis, bem como a capacidade de adaptar e moldar os novos processos de trabalho e as novas tecnologias.

Com isto, há uma mudança na forma de se conceber os currículos profissionalizantes. Se anteriormente estes eram derivados de uma teoria de racionalidade técnica ou de um conjunto pré-definido de conhecimentos, para os quais era esperado o desempenho de uma grande variedade de tarefas previsíveis e rotineiras, a pesquisa mais recente aponta no sentido de se dar maior relevância à capacidade de resolver problemas imprevistos e de desenvolver novos conhecimentos.

Essa mudança de perspectiva leva à adoção do modelo de competência, em todas as reformas analisadas, inclusive a brasileira, e ele necessita ser problematizado, uma vez que são identificados diferentes sentidos para a noção de competência no debate atual.

Para se compreender esse conceito, e sua aplicação nas reformadas pesquisadas, é necessário perceber que a relação entre empregabilidade e aprendizagem ao longo da vida passa pela estruturação de um sistema de competências que oferece essa sustentação. Podem ser identificados, como elementos básicos desse sistema, as normas, as quais refletem qualificações requeridas, um sistema confiável de avaliação e qualificações e um sistema de certificação de qualificações reconhecido e transferível entre setores.

Trevisan (2001), ao analisar a relação educação e trabalho na Inglaterra, nos mostra que o modelo de modernização, iniciado pela conservadora Thatcher, teve continuidade com o trabalhista Blair, e, copiado por muitos, tem como seu elemento estruturador a privatização, enquanto política econômica que atinge diretamente a força de trabalho.

Os sistemas flexíveis de produção, característicos do início dos anos 1980, demandavam um perfil completamente novo de estrutura produtiva. A primeira característica era a exigência de quantidade muito menor de trabalhadores no local de trabalho. Depois, a especialização de função pouco a pouco 
começou a ser abandonada e, com a redução do número de trabalhadores, iniciou-se o processo de procura pelo trabalho multi-habilitado. $\mathrm{O}$ vínculo educação/empregabilidade passa a ser uma opção de política pública, através de aquisição de competências.

Foi nesse contexto que o conceito de empregabilidade avançou, sendo definido como o conjunto de habilidades profissionais que diferencia o trabalhador e que o torna "empregável" pelo interesse que desperta no empregador, devido a seu conhecimento acumulado e diversificado. Desde o início dos anos 1990, a construção de habilidades transferíveis no trabalhador tornou-se o foco tanto para o desenvolvimento de políticas públicas quanto para o treinamento nas empresas para a formação de mão de obra.

Trevisan ainda revela, a partir do caso inglês, vivenciando um momento de constante troca de padrão tecnológico, que a empresa, sem saber exatamente que tipo de habilidade esperar do empregado, devolve esse "problema" para o sistema educacional. O empregador, pensando nos custos da formação, e o empregado, procurando a certeza de retorno do investimento educacional que pretende fazer, pressionam a instituição escolar para que acompanhe as mudanças tecnológicas, exigindo que a educação forneça os parâmetros, os padrões e as certezas que o mercado não consegue oferecer.

Zarifian (2003) resgata a trajetória histórica do modelo de competência e nos mostra que, nos anos 70, ele surge ainda de maneira implícita. Aparece um paradoxo com o surgimento de novos critérios de classificação (responsabilidade, autonomia e exigência de formação). Esses critérios são decisivos e são completamente novos em relação ao critério clássico de complexidade de atividade. Neste, é o modo de construção da qualificação que o caracteriza, e não o seu nível; entretanto, ele afirma, são os empregos que continuam sendo avaliados e classificados, ou seja, os indivíduos permanecem classificados segundo o emprego (posto de trabalho) que ocupam.

Nos anos 80, o modelo aparece, explicitamente, impulsionado por dois elementos-chave: sair da crise, por uma alta qualidade dos produtos, personalização da relação com os clientes e complexificação do desempenho, e enfrentar o crescimento da incerteza. Nesse contexto, Zarifian (2003) identifica uma resposta burocrática dos gestores de Recursos Humanos, montando sistemas complexos de gestão de competências, sem romper, no entanto, com a qualificação do emprego. Com isso, ele identifica a existência de modelos híbridos de competência, com uma visão mais diretamente econômica, que é o caso das reformas analisadas.

Com isso o autor define o que é competência, a partir dos elementos essenciais que a caracterizam: a tomada de iniciativa e responsabilidade do indivíduo em situações profissionais com as quais se confronta; uma 
inteligência prática das situações, que se apoia em conhecimentos adquiridos e os transforma, à medida que a diversidade das situações aumenta; faculdade de mobilizar redes de atores em volta das mesmas situações, de compartilhar desafios, de assumir áreas de responsabilidade; iniciativa e o assumir de responsabilidade do indivíduo sobre problemas e eventos que ele enfrenta, em situações profissionais.

Com base em Zarifian (2003), podemos concluir que o modelo de competência está relacionado à superação do modelo de posto de trabalho, e as reformas analisadas não revelam ainda essa superação, por não terem completado o processo de transição.

Kuenzer (2008), com base em Zarifian (2003), explica a significativa mudança na compreensão do que seja competência, a partir do modelo de acumulação flexível, gerado pela revolução tecnológica. Esse modelo combina modos de organização e gestão do trabalho tayloristas / fordistas aos toyotistas, de forma a assegurar a melhor combinação entre trabalho qualificado e trabalho precário.

Para a autora, essa mudança de concepção impacta fortemente a educação profissional, que passa a ter outra especificidade. Se competência, no taylorismo-fordismo, era fundamentalmente conhecimento tácito advindo da experiência e de natureza psicofísica, em face das novas tecnologias, passa a significar capacidade de trabalhar intelectualmente, de modo a enfrentar os problemas da prática laboral e social. Para isto, se demanda conhecimento teórico. Essa dimensão da competência é nova, e, por contradição, não atende necessariamente apenas ao capital, uma vez que impacta positivamente a formação dos trabalhadores.

Além do desenvolvimento da pedagogia das competências, preconizado pelas reformas, podemos destacar também a questão da formação em contexto de trabalho, uma inspiração britânica com o desenvolvimento do projeto work experience, impulsionado como "tarefa de Estado" e que obriga os alunos do ensino básico, a partir dos 14 anos, a conhecer os locais de trabalho.

Nas palavras de Trevisan (2001, p. 37), “a construção dessa política pública que reformasse a função e o sentido da educação compulsória oferecida pelo Estado teria de possuir uma perspectiva política. A ideia de empregabilidade faz essa ligação. O que se pretendia era forçar a 'aquisição de habilidades', como função, e uma 'cultura empresarial', como sentido, ambas com declarada perspectiva política".

Segundo Kuenzer (1999), o conhecimento tácito é orgânico a um modo de organizar e gerir o trabalho que se estrutura sobre a relativa estabilidade dos processos, em face da reduzida dinamicidade da tecnologia sobre a fragmentação dos processos e sobre o saber fazer. No entanto, em um contexto de 
acumulação flexível, é necessário o desenvolvimento do que a autora denomina competências cognitivas complexas. Estas se referem menos ao saber fazer do que ao domínio do raciocínio lógico-formal, da capacidade de trabalhar com as ideias, das competências comunicativas, do domínio das linguagens, a partir da capacidade de análise, síntese, criação de soluções inovadoras, rapidez de resposta, comunicação clara e precisa, interpretação e uso de diferentes formas de linguagem, capacidade para trabalhar em grupo, lidar com as diferenças, enfrentar os desafios das mudanças permanentes, resistir a pressões, buscar aprender permanentemente, e assim por diante.

A partir dessas mudanças, para a autora se estabelece uma aparente contradição: quanto mais se simplificam as tarefas, mais se exige conhecimento do trabalhador, e não apenas tácito. Ao contrário, a crescente complexificação dos instrumentos de produção, informação e controle, nos quais a base eletromecânica é substituída pela base microeletrônica, passa a exigir o desenvolvimento de competências cognitivas complexas. Nesse modo de conceber a categoria competência, a partir das demandas da acumulação flexível, é importante destacar que não desaparece a relevância do conhecimento tácito em nome da supremacia do conhecimento científico, mas sim se restabelece a dialética entre teoria e prática.

\section{Linhas orientadoras dos sistemas nacionais de educação e formação nos países estudados}

Ao analisar as reformas dos países selecionados, ganha destaque o papel da OCDE (Organização para a Cooperação e Desenvolvimento Econômico). Pode-se observar um conjunto de ações que explicitam as razões para o desencadeamento das reformas em seus países membros e também naqueles que, embora não pertençam à comunidade europeia, seguiram a sua orientação, como é o caso da Coreia do Sul.

O Conselho Europeu, em reunião extraordinária em Lisboa, em março de 2000 (PORTUGAL, 2003), definiu como objetivo a alcançar até 2010, para os sistemas de educação e formação europeus, a necessidade de se adaptarem não só às exigências da sociedade do conhecimento, como também à necessidade de um maior nível e qualidade do emprego. Esse objetivo foi retomado, em fevereiro de 2002, pelos Ministros responsáveis pela educação e formação de países da União Europeia e pela Comissão Europeia no sentido de, até 2010, esses sistemas atingirem a máxima qualidade na educação, tendo em vista que a Europa seja reconhecida como referência em qualidade e relevância dos sistemas e instituições de educação e formação, em âmbito mundial. 
Dessa perspectiva, a aprendizagem ao longo da vida passa a ser o princípio orientador da oferta e da participação em um continuum, permitindo, a todos os europeus, o benefício de oportunidades idênticas para se adaptarem às exigências das mutações sociais e econômicas, a partir da promoção de uma cidadania ativa e do reforço da empregabilidade.

A Educação Profissional foi considerada, então, como modalidade do ensino secundário que contribui e reforça, com sua especificidade, a consecução desse objetivo estratégico, tanto no que se refere ao aumento da qualidade das aprendizagens, quanto no combate ao insucesso e abandono escolares, em resposta aos desafios da sociedade da informação e do conhecimento.

\subsection{Portugal}

Um elemento central da experiência das escolas profissionais em Portugal são as ideias sobre o desenho curricular para os cursos de nível secundário. Essa matriz curricular, debatida em 2003 (PORTUGAL, 2003), foi iniciada no ano letivo 2004-2005 e afirma a identidade do Ensino Profissional - EP, como uma forma de dotar os jovens de um conjunto de saberes humanísticos, científicos e técnicos que lhes permitam exercer de forma ativa o seu papel de cidadãos e lhes possibilite uma efetiva inserção no mercado de trabalho.

Essa reformulação da oferta formativa do Ensino Profissional resultou na adequação dos perfis profissionais, atuais e emergentes, no quadro de uma identificação de áreas prioritárias e estratégicas para o desenvolvimento econômico e social do país, por meio da criação de um Catálogo Nacional de Qualificações e de um Catálogo Modular de Formação Profissional atualizados periodicamente.

É importante destacar que a definição da matriz curricular numa perspectiva de aproximação das outras modalidades do ensino secundário facilita a permeabilidade entre os diferentes percursos formativos, ao mesmo tempo em que busca resguardar a especificidade do ensino profissional em qualquer das componentes da formação.

Cabe destacar, ainda, a concepção de referenciais de formação adotada, mediante a busca de aquisição de competências-chave, competências transversais a perfis profissionais comuns, e competências específicas do perfil profissional.

Em Portugal, a avaliação é de que, ao longo dos anos, os sucessivos ajustes valorizaram sempre mecanismos de aproximação entre os estabelecimentos de ensino, as instituições econômicas, financeiras, profissionais, associativas, sociais ou culturais do tecido social local e regional, constituindo-se como fator potencial de desenvolvimento, no contexto de uma sociedade e economia do conhecimento e da inovação. 
Nesse sentido, o Ensino Profissional tem sido ministrado quase que exclusivamente em escolas profissionais privadas, de pequena dimensão, com um projeto próprio e organização específica, criadas como resultado da conjunção de esforços de âmbito local e regional (autarquias, empresas, associações comerciais e industriais).

\subsection{Austrália}

$\mathrm{Na}$ Austrália, a necessidade de um sistema nacional de qualificação e formação profissional surge em função das mudanças ocorridas na economia na década de 80, exigindo trabalhadores com capacidade de mobilidade e adaptação à nova realidade, tendo por base normas de competência. Nesse sentido, a criação de um marco nacional de qualificações serviu como uma referência a empresas e trabalhadores para uma educação ao longo da vida e uma adequação entre demanda e oferta e escolha das carreiras (AUSTRÁLIA, 1995).

O Sistema Nacional de Competências foi adotado em 1989, inspirado na experiência britânica, porém com características próprias, pois, no caso da Austrália, mais do que uma determinação governamental, houve uma participação e negociação entre os agentes envolvidos: governo, empresários e sindicatos. Foram estabelecidos três tipos de normas: as intersetoriais, as específicas de um setor e as normas por empresa. Sete competências-chave foram identificadas e consideradas comuns à força de trabalho: a) buscar, analisar e organizar informação; b) comunicar ideias e informação; c) planejar e organizar atividades; d) trabalhar com outros e em equipe; e) utilizar técnicas e conceitos matemáticos; f) resolver problemas; g) utilizar tecnologia.

A Austrália decidiu constituir e desenvolver um sistema de educação e formação profissional gerido por empresários e empresas dos setores produtivos que intervêm nos diferentes planos da realidade do mercado de trabalho, como o nacional e o dos estados e territórios. Além disso, em âmbito local, começou-se a trabalhar com as empresas, através de institutos técnicos de formação profissional, a partir das necessidades de formação detectadas pelas próprias indústrias. Essa política tem conseguido atrair cifras de até $60 \%$ de investimento em formação pelos empresários em planos de formação para seus empregados.

Algumas condicionantes de implantação podem ser identificadas, tendo em vista o início do processo na década de 1980. Há dificuldades e lentidão no processo de convencimento dos atores envolvidos, empresários, trabalhadores e educadores. A necessidade da mudança é percebida, mas a sua efetivação requer um "timing" específico. Há desconfiança em relação à educação por competências, principalmente por parte dos educadores, que sentem a 
falta de um suporte teórico pedagógico mais consistente. Existe dificuldade na compreensão, por parte de muitos gestores, das implicações das mudanças para uma gestão por competências, o que não é automático. Ocorre dificuldade de alinhamento de todos os setores com os objetivos da reforma educacional para evitar contradições, na medida em que se lida com diferentes setores e necessidades, com diferentes níveis de absorção. As regulamentações que asseguram a qualidade também podem dificultar a inovação. Trata-se de uma tensão presente em qualquer processo em desenvolvimento. Nesse sentido, as normas devem ser suficientemente flexíveis para permitir a absorção das inovações inerentes, inclusive, ao próprio paradigma social para o qual as modificações vêm sendo feitas.

\subsection{Canadá}

No Canadá, a exemplo dos demais países analisados, a reforma educativa em geral e da educação profissional e vocacional, em particular, parte do pressuposto de que a tendência da educação profissional é favorecer o domínio do conhecimento, nessa transição da era industrial para a era da informação.

Entretanto, o Canadá tem uma característica diferenciada em relação aos demais países estudados e que marca profundamente a sua reforma: a educação é uma responsabilidade provincial, e esse nível de descentralização tem acarretado um conjunto de problemas no que se refere ao reconhecimento das diversas formas de aprendizagem e, por consequência, à mobilidade dos trabalhadores, restringindo o seu potencial de desenvolvimento profissional e econômico. A solução para esse problema, qual seja o reconhecimento das diferentes formas de aprendizagem, converteu-se, assim, no eixo central de grande parte das políticas e esforços desenvolvidos nos últimos anos em matéria de desenvolvimento profissional dos trabalhadores, com repercussões nos sistemas de educação e formação profissional, bem como no âmbito da produtividade (CANADÁ, 2004).

No Canadá, um dos problemas centrais na discussão sobre a necessidade de reforma diz respeito às aprendizagens informais, ou seja, aquelas que não são reconhecidas por um diploma ou certificado, e que estão relacionadas a um grupo de trabalhadores que dedicam uma parte do seu tempo ao desenvolvimento de atividades de aprendizagem, vinculadas com sua situação de trabalho (SOUSA, 2002). No entanto, as empresas preferem reconhecer formações do tipo formal. Fazem parte desse grupo trabalhadores autônomos, trabalhadores em setores da pequena e média empresa, pessoas mais velhas e com nível educacional mais baixo.

Essa dificuldade tem sido enfrentada nas reformas de diferentes países, com o crescente reconhecimento do saber tácito, ou do saber adquirido no 
trabalho, e através de reformas curriculares, onde a formação no contexto de trabalho passa a se constituir num componente da formação geral e profissional.

Com relação à aprendizagem formal, o problema reside, de um lado, na grande mobilidade do mercado de trabalho canadense e, de outro, nos problemas colocados à "livre circulação", dos trabalhadores, pela inexistência de sistemas de reconhecimento eficientes e eficazes que estimulem o aprendizado permanente, mas que evitem duplicidades entre os distintos sistemas de reconhecimento e de formação existentes no território canadense.

Como se pode perceber, o grande desafio colocado para a reforma canadense é a superação das barreiras existentes no reconhecimento das qualificações e que quebra o princípio da flexibilidade e da permeabilidade do sistema, que tem caracterizado as reformas em âmbito mundial. Ou seja, os trabalhadores canadenses têm dificuldade para transferir suas competências a outro território diferente daquele onde obtiveram sua certificação.

Nesse sentido, o conjunto de problemas motivadores da reforma está associado ao reconhecimento de diversas formas de aprendizagens e das dificuldades que isto gera, seja quanto à mobilidade do trabalhador, seja em relação ao desenvolvimento do seu potencial profissional e econômico. Claro que na base dessa questão está a inexistência de um sistema nacional de formação e qualificação profissional.

Segundo o Ministério da Educação de Quebec (CANADÁ, 2002), algumas propostas de melhoria do sistema de reconhecimento e acreditação têm sido feitas. Em 2002, a "Conference Board of Canadá" constatou que havia 540.000 canadenses desempregados devido à falta de reconhecimento de suas aprendizagens e propôs melhorar o funcionamento das instituições existentes, criar novas instituições, técnicas e instrumentos, e comprometer a participação dos empresários.

Ainda segundo o Ministério da Educação, o Centro de Trabalho e Negócios do Canadá, organização que compreende os líderes de trabalho e negócios de todas as regiões e de um amplo espectro de indústrias e setores econômicos do país, tem proposto atuação em três níveis.

No nível do Governo Federal, propõem-se mudanças na oferta existente de formação que afetam o sistema de aprendizes. Trata-se de facilitar a formação no setor de comércio e vendas, subvencionando as ferramentas do trabalho dos pequenos comerciantes e reformando o seguro dos aprendizes durante seu período formativo. Propõe-se também um novo enfoque no desenvolvimento de recursos humanos, com um possível incentivo fiscal no investimento em formação, e uma iniciativa em constituir um Registro com Quotas de Aprendizagem Industrial. São sugeridas, ainda, atuações em 
políticas de imigração, com o desenvolvimento e implementação de critérios de reconhecimento de qualificações mais flexíveis, e outras iniciativas mais especificas dirigidas a determinados setores.

No nível provincial, os planos contemplam medidas dirigidas ao ensino elementar e secundário, como incorporar competências do trabalho nos programas educativos ou introduzir o conceito de empregabilidade no âmbito escolar. Pretende-se que o ensino secundário seja mais consciente e receptivo às necessidades de formação da indústria.

No nível dos negócios, pretende-se realizar um esforço maior na formação, orientada para a modularização dos conteúdos, busca de um sistema mais efetivo de aprendizagem e empreendimento de ações para o reconhecimento das qualificações no território canadense.

\subsection{Coreia do Sul}

A Coreia do Sul, pertencente ao grupo dos países chamados de "Tigres Asiáticos", apresentou uma estrutura agrícola até 1960. A partir de uma forte decisão política centralizada, industrializou-se sob o comando de um estado desenvolvimentista, com a economia voltada para a exportação. Como consequência, passou a apresentar taxas anuais de crescimento econômico bastante elevadas considerado o nível mundial, principalmente dos países desenvolvidos. No entanto, em meados da década de 1990, entrou em forte crise econômica, necessitando de uma intervenção do Fundo Monetário Internacional. Como consequência, começou a apresentar baixas taxas de crescimento, elevação do nível de desemprego e desvalorização do Won, sua moeda nacional.

Em 1996, dentro desse contexto, o país associou-se à Organização para a Cooperação e Desenvolvimento Econômico (OCDE), como seu $29^{\circ}$ membro, e essa organização terá forte influência nas reformas, principalmente educacional (OCDE/Korea). Em 1998, pela primeira vez em 50 anos, ocorreu uma alternância no poder, assumido pelo partido de oposição, embasando-se em duas posições: fortalecimento da democracia, a partir de uma economia de mercado, e a realização de reformas extensivas, principalmente no campo educacional. A percepção da ocorrência de um processo de mudança de uma economia industrial, de base material, para uma economia de serviços, com base no conhecimento, passa a direcionar a agenda da política governamental como sustentação de suas reformas. No campo educacional, pensa-se a mudança para uma sociedade de educação aberta, com uma aprendizagem ao longo da vida.

Do ponto de vista da Reforma Educacional, em junho de 1998, foi nomeada a Comissão Presidencial para a Nova Comunidade Educacional, encarregada 
de propor estratégias e ações no sentido de alcançar os objetivos estabelecidos pelo governo para a sociedade.

A Coreia do Sul teve sua reforma educacional bastante influenciada pela OCDE, a qual fez doze recomendações que embasaram as ações futuras. As duas primeiras recomendações abordam, principalmente, a questão das condições de trabalho na educação, sejam elas físicas ou profissionais. A ênfase está em um planejamento do investimento a ser realizado, a partir de planos quinquenais, iniciados em 1998.

Outra recomendação trata da questão da avaliação, tanto institucional, tendo por base a escola, quanto dos gestores locais. Define, também, os parâmetros comuns, missão atribuída a um dos institutos criados, no caso o de desenvolvimento educacional (KEDI).

Outra preocupação diz respeito à qualificação e recrutamento de professores, a partir de um plano geral de desenvolvimento. Junto a isso, reforça a organização dos professores como agente a influenciar a política educacional. Mais do que uma política definida por tecnocratas, a ênfase está na participação dos professores na sua formulação e implementação.

Do ponto de vista da formação profissional, existe a recomendação da expansão das disciplinas acadêmicas nos colégios vocacionais, até se chegar a um sistema integrado para o ensino médio. O piloto com escolas funcionando com currículo independente pode ser uma iniciativa interessante nesse processo. Além disso, sugere-se uma orientação nacional que cuide do sistema de qualificação, como já existente em outros países da OCDE.

No âmbito do ensino superior, a inovação estaria na criação de novas universidades ligadas ao setor industrial, com o mesmo status das instituições educacionais regulares. Isso conferiria às universidades corporativas o poder de certificação.

A utilização das TIC na educação passa a ser prioridade, principalmente em uma perspectiva de aprendizado ao longo da vida. Para a implementação dessa recomendação, atribuem ao KERIS (Korean Education and Research Information Service), que gerencia o sistema de informação educacional, a operação da EDUNET (sistema da rede educacional), funcionando desde 1997, além da inauguração, em 1996, da Open University Network, na Korea National Open University.

O apoio à pesquisa educacional configura-se como outra importante recomendação, na medida em que a educação só avança tendo por base a pesquisa. Nesse sentido, ressalta-se a liderança de um dos institutos, no caso o KEDI.

As três últimas recomendações são mais específicas no que diz respeito aos cuidados, tanto nos critérios quanto na utilização dos resultados da avaliação, ao apoio a estudantes de baixo poder aquisitivo, além da manutenção 
de um sistema de informação educacional bem organizado para atender os interessados.

De uma maneira geral, as recomendações tocam em pontos-chave do que vem acontecendo com as reformas educacionais no mundo: a preocupação com a qualificação dos professores e sua participação na formulação e implementação de políticas, bem como um planejamento mais rigoroso no desenvolvimento de condições para sua atuação; a utilização, de forma mais intensiva, das TIC na educação; a questão da avaliação, de forma geral; a preocupação com a educação vocacional e seus desdobramentos, incluindo a possibilidade de formação profissional pelas universidades corporativas; a ênfase na organização de um sistema de informação que permita acesso aos consumidores da educação; além de preocupações mais específicas com estudantes carentes.

As propostas coreanas foram dirigidas, entre outras finalidades, para a criação de uma nova cultura escolar, estimuladora da criatividade e da inovação, pilares da sociedade do conhecimento; o estabelecimento de um conselho escolar, aproximando não só os diversos segmentos da comunidade escolar, mas também os pais dos alunos e a própria comunidade ao redor da escola; a revisão curricular, mais centrada no aluno e no desenvolvimento de seu potencial, com o professor atuando como facilitador desse aprendizado; diversificação dos métodos de avaliação do aluno para além da aplicação de testes, simplesmente, e toda a tensão daí decorrente; investimento na melhoria e atualização profissional do professor, associado à construção de um sistema de avaliação das instituições de formação de professores, preocupado com a manutenção de sua qualidade.

A educação profissional, englobada no rótulo de educação vocacional e técnica, também se constituiu em foco das reformas. Partiu-se do princípio da criação de um sistema bancário de créditos educacionais, possibilitando maior flexibilização na trajetória de formação e certificação do aluno para além da escola regular, abrindo espaço para uma participação mais ativa do próprio mercado de trabalho em oportunidades de formação profissional do aluno. Propôs-se, também, o desenho de um novo sistema de qualificações, a partir do estabelecimento de três leis principais: a) a Lei da educação vocacional e promoção do treinamento; b) a Lei fundamental de qualificações; c) a Lei do Korean Research Institute for Vocational Education and Training (KRIVET).

No que se refere à educação vocacional, foram propostas a criação das "novas universidades", renomeadas para "technical colleges", abrindo a possibilidade para sua implantação a partir das corporações industriais, com o mesmo status das universidades regulares. Esses "technical colleges" poderão 
dar um embasamento mais efetivo, em nível superior, às universidades corporativas. Além disso, abrem a possibilidade da adoção do "comprehensive high school system", o qual permitirá maior mobilidade entre um currículo mais acadêmico e um outro mais profissionalizante.

A percepção do governo está na necessidade de conferir maior peso a cursos acadêmicos no currículo do secundário vocacional. Dentro dessas reformas, ainda não foi criada, diferente de outros países da OCDE, uma única autoridade com a responsabilidade pelas qualificações nacionais. Dentro desse objetivo, abriu-se a possibilidade do estabelecimento de um Comitê de Política de Qualificação, sendo as qualificações nacionais geridas por 24 órgãos, entre ministérios, escritórios e agências.

A outra grande ênfase definida pelo governo coreano está na utilização das tecnologias da informação e comunicação (TIC) na educação. Tendo em vista a opção de uma educação aberta ao longo da vida, criou-se a Lei da Educação ao Longo da Vida, em 1999, base para um sistema de educação aberta. Com isso, vislumbra-se a possibilidade de expansão das TIC para além das instituições tradicionais de educação a distância, como a "Air Correspondence High School" ou a "National Open University". A proposta é criar um "Cyber Education System", que possibilite maior exploração do potencial da educação a distância a partir das TIC.

A criação do KRIVET, em 1997, constituiu-se em parte de um conjunto de institutos destinados ao desenvolvimento da educação no país. Iniciado pelo Korea Education Development Institute (KEDI), de criação mais antiga, desde 1972, associaram-se, além do KRIVET, o Korea Institute of Curriculum and Evaluation (KICE) e o Korea Education and Research Information Service (KERIS), todos criados na segunda metade dos anos noventa. Do ponto de vista da política educacional, percebe-se a intenção de sua implementação tendo por base o foco de cada um desses institutos, tanto do ponto de vista da pesquisa, quanto da oferta de serviços, articuladas com o desenvolvimento do conhecimento pelas universidades. Nesse sentido, o foco na educação vocacional e treinamento, no currículo e avaliação, no sistema de informação e, mais amplamente, no desenvolvimento do sistema educacional, oferecem a direção pensada pelo governo.

\section{Contribuições ao debate sobre o tema para a reforma no Brasil}

Diante dessas descrições das reformas propostas para a organização da educação profissional e tecnológica, a partir de quatro realidades encontradas em países com origens e desenvolvimento bem distintos, que aspectos podemos ressaltar como contribuições relevantes para a compreensão e o debate que já vem ocorrendo na reforma brasileira para essa área? 
Parece evidente, apesar das diferenças, a convergência na interpretação do contexto onde mudanças e soluções são propostas. A revolução nas tecnologias de informação e comunicação (TIC) e a consequente reestruturação capitalista de uma economia industrial, com base material, para uma economia de serviços, com base no conhecimento, passam a embasar a agenda da política governamental de sustentação das reformas, percebendo-se a educação na perspectiva de um aprendizado ao longo da vida e da inclusão educacional, com abrangência universal.

O exemplo da Austrália, derivado do modelo inglês, nos mostra a necessidade de um marco nacional de qualificações que sirva como referência para empregadores e trabalhadores a uma adequação entre a demanda, oferta e escolha de carreiras. Isso traz o conceito de competência para o centro da relação entre empregabilidade e aprendizagem ao longo da vida, solicitando a construção de um sistema de competências constituído por normas que reflitam as qualificações requeridas, uma avaliação confiável e um sistema de certificação de qualificações reconhecido e transferível entre setores.

No entanto, aponta também para potencialidades e limites. A importância da participação dos diferentes atores sociais na construção das soluções de reforma, diferente do modelo inglês, é contrabalançada pela dificuldade de convencimento de determinados grupos, principalmente aqueles ligados à área educacional, e com resistência em aceitar o modelo de currículo por competência. Como se viu, em seção anterior, a compreensão, aceitação e debate sobre esse conceito, e seu modelo consequente, continuam em aberto, requerendo maior aprofundamento e discussão para uma real apropriação de forma crítica e que permita maior consistência necessária para a formação do trabalhador e o desenvolvimento do país.

No Brasil, percebe-se essa dificuldade de articulação entre atores (CARVALHO, 2008) em relação à proposta de um sistema nacional de certificação profissional, apresentada em agosto de 2005, pela Comissão Interministerial de Certificação Profissional, composta pelos Ministérios do Trabalho e Emprego, Educação, Desenvolvimento, Indústria e Comércio Exterior, Saúde, Turismo e os Conselhos Nacionais da Educação e do Trabalho. Embora bem articulada e colocada na agenda governamental, não conseguiu o impulso necessário para sua implantação, principalmente na articulação entre os diversos entes governamentais e no debate com a sociedade.

O Canadá nos aponta para a dificuldade da descentralização política, pois lá as definições e implementações ocorrem no nível provincial, trazendo problemas ao reconhecimento das diversas formas de aprendizagem e, por consequência, à mobilidade dos trabalhadores. Como superação, vem propondo melhorar o funcionamento das instituições existentes, criar novas 
instituições, técnicas e instrumentos e comprometer a participação dos empresários.

Essa questão do relacionamento entre as esferas federal, estadual e municipal, no caso brasileiro, ainda não alcançou o nível de descentralização canadense, mas já avançou nessa direção, com a Constituição de 1988 (BRASIL, 1988), principalmente em termos de municipalização e maior autonomia aos entes federados. Nesse caso, o Canadá pode ser visto como uma referência na busca por soluções descentralizadoras, a partir de uma necessidade de um sistema nacional. No entanto, é preciso lembrar que a descentralização também coloca problemas e limites que precisam ser entendidos para que possam nortear qualquer política pública desejada.

A Coreia do Sul nos oferece um exemplo de como o investimento em educação, de forma geral, e na educação profissional e tecnológica, em particular, a partir de uma determinação política centralizada, permitiu a evolução rápida de uma sociedade, agrária até 1960, para outra baseada em serviços e nas tecnologias da informação e comunicação. Sem dúvida, a sua filiação à OCDE, em 1996, acabou orientando sua reforma. Do ponto de vista curricular, vem propondo a mudança na cultura escolar, de forma a permitir maior criatividade e inovação, fatores fundamentais em uma sociedade com base no conhecimento. Além de fortalecer o conselho escolar e criar maior proximidade com os pais e comunidade local, vem revisando o seu sistema de avaliação, tornando-o mais diversificado.

Tendo por base uma legislação que criou diferentes institutos, pode direcionar o foco da educação profissional para mudanças curriculares e de avaliação, para a criação de um sistema de informação a partir das TIC, o "cyber education system", bem como investir em pesquisa educacional para o fortalecimento da base de conhecimentos para o desenvolvimento educacional no país.

Para o Brasil, a Coreia mostra a relevância da indução da política da educação profissional e tecnológica, a partir do governo federal. Nesse caso, a decisão política central ajudou no impulso necessário ao desenvolvimento da educação no país. Mostra-se interessante, também, a perspectiva da busca pela criação e articulação de novas instituições que permitam desenvolver o que se tornou fundamental no século XXI: um sistema de informação e comunicação avançado e o investimento em pesquisa na educação, garantindo um conhecimento fundamental para a compreensão e intervenção no processo de mudança da sociedade.

Nessa direção, Portugal criou o Plano Tecnológico de Educação, como estratégia para até 2010 colocar o país entre os cinco mais avançados ao nível de modernização tecnológica do ensino. 
Esse país constituiu um subsistema de ensino profissional em uma trajetória de consolidação, integrando-se ao sistema de ensino secundário. Criou um sistema nacional de certificação profissional, assegurando um certificado para qualquer profissional que demonstre possuir as competências necessárias ao exercício da profissão. Mas o mais importante foi articular a política de formação profissional a uma política de emprego, colocando juntos o Ministério da Educação e o Ministério da Segurança Social e do Trabalho, e todos os órgãos relacionados.

Sem dúvida Portugal aponta, no caso brasileiro, para uma questão central. Além da necessidade de criação de um sistema nacional de certificação, que no Brasil, como vimos, está dando seus primeiros passos, focou sua política na articulação entre o Ministério da Educação e do Trabalho, lá associado à Segurança Social. Talvez esse seja um dos pontos relevantes que mais atenção a política brasileira para a educação profissional e tecnológica deva dar. Acrescente-se o fato de que, no Brasil, temos o Ministério do Trabalho e Emprego, que, sem dúvida, permite associar uma política educacional, não só ao trabalho, mas também à geração de emprego e renda.

De forma geral, pode-se perceber um caminhar internacional das reformas educacionais e da educação profissional e tecnológica, especificamente, na direção do fortalecimento desse nível educacional e sua consideração como marco estratégico para o desenvolvimento de cada país. Mudanças na relação com o ensino médio, com a educação superior tecnológica e com o mercado de trabalho podem ser consideradas como desafios para a realidade brasileira, que também caminha em uma direção convergente com a perspectiva internacional, a partir de políticas como currículo médio integrado, a criação recente dos Institutos Federais de Educação Profissional e Tecnológica, a criação dos catálogos de cursos para tecnólogos e técnicos, a associação entre a educação de jovens e adultos e a formação para o trabalho e qualificação profissional, no Proeja, e a utilização das TIC na educação e seus impactos pedagógicos.

Nesse sentido, cabe salientar uma especificidade da expansão da educação profissional, no caso brasileiro, se comparada aos demais países analisados. Aqui registramos, a exemplo dos demais países, um forte incremento na expansão das atividades de educação profissional, mas, numa tendência inversa aos demais casos, essa expansão se dá com o fortalecimento do setor público, e não pela ampliação da privatização dessas ações.

Percebe-se, todavia, que, apesar desse fortalecimento da educação profissional e tecnológica como responsabilidade do Estado, existem fatores que fragilizam a tendência de se trabalhar com a visão de um sistema nacional que permita a articulação adequada e sinérgica entre as diferentes esferas 
governamentais, diferentes ministérios e órgãos públicos e outras esferas da educação profissional. Com isso, mantêm-se diferentes redes de educação profissional no país, reforçando-se o dualismo que sempre caracterizou esse nível de ensino, agora sob nova aparência. Da perspectiva do setor público, temos, de um lado, a rede pública de educação profissional e tecnológica, vinculada ao Ministério da Educação, responsável pelo ensino regular/formal nessa modalidade de ensino, em seus diversos níveis. De outro, o Ministério do Trabalho e Emprego, ofertando também a formação profissional, especialmente em sua versão de educação continuada. Deve ser considerada, ainda, a esfera privada com a rede de Educação Profissional e Tecnológica ligada ao denominado sistema S (Senai, Senac, Sesi, Sesc, Senat), historicamente apoiada com financiamento público, além das entidades sindicais, que atuam, via de regra, com recursos do Fundo de Amparo ao Trabalhador, sob a gestão do Ministério do Trabalho e Emprego.

Esse quadro revela a necessidade de integrar essas ações de educação profissional em um Sistema Nacional de Educação e Qualificação Profissional que permita ações descentralizadas entre os diferentes atores, porém com uma coordenação que possibilite uma sinergia para uma formação mais adequada do trabalhador e o atendimento das demandas locais, regionais e nacionais.

Trata-se de aprofundarmos cada vez mais o debate, a partir de experiências que demonstrem o potencial para o alcance dos objetivos educacionais mais amplos estabelecidos pela sociedade brasileira, principalmente para a educação que o Brasil pretende desenvolver ao longo do século XXI (DELORS, 2002).

\section{Referências}

AUSTRÁLIA. Australian Qualifications Framework, jan. 1995.

BRASIL. Constituição: República Federativa do Brasil. 1988: Texto constitucional de 5 de outubro de 1988 com as alterações adotadas pelas Emendas Constitucionais $\mathrm{n}^{\circ}$ 1/92 a 4/93. Brasília: Senado Federal, Centro Gráfico, 1993.

CANADA. Analyse Comparative des Modèles de Formation Professionnelle et Tecnique au Quebec e dans d'Autres Etats. Quebec: Ministère de l'Éducation, 2002.

. Qualification Professionnelle. Quebec, 2004. Document de Référence.

CARVALHO, Olgamir Francisco. Tendências da relação Trabalho/Educação no contexto da globalização. In: BRASIL. MEC. INEP. Formação de professores para a educação profissional e tecnológica. Brasília: Inep, 2008. p. 141-155 (Coleção Educação Superior em Debate, v. 8).

DELORS, Jacques. Educação: um tesouro a descobrir. 7. ed. São Paulo: Cortez, 2002. 
DUPAS, Gilberto. Economia global e exclusão social. São Paulo: Paz e Terra, 1999.

KUENZER, Acácia Zeneida. Educação profissional: novas categorias para uma pedagogia do trabalho. Boletim Técnico de Senac, Rio de Janeiro, v. 25, n. 2, p. 19-29, 1999.

; FRANCO, Maria Ciavatta; MACHADO, Lucília Regina de Souza. Formação de professores para a educação profissional e tecnológica: perspectivas históricas e desafios contemporâneos. In: BRASIL. MEC. INEP. Formação de professores para a educação profissional e tecnológica. Brasília: Inep, 2008. p. 17-82. (Coleção Educação Superior em Debate, v. 8).

LIPIETZ, Alain. Towards a new economic order. Cambridge: Polity Press, 1992.

PORTUGAL. Ministério da Educação. Ensino Secundário: Documento Orientador da Revisão Curricular do Ensino Profissional. Lisboa: abril de 2003. Versão para discussão pública.

SOUSA, Luzia Costa. Estudo Comparado da educação profissional: Alemanha, Argentina, Canadá, França e Cuba. In: LEITE, Elenice Monteiro; SOUZA, Francisco Heitor de Magalhães (Orgs.). Centros Públicos de Educação Profissional: teoria, propostas, debates e práticas. Brasília: Edunb, 2002, p. 103-124.

TREVISAN, Leonardo. Educação e trabalho: as receitas inglesas na era da instabilidade: São Paulo: Senac, 2001.

ZARIFIAN, Philippe. O modelo da competência: trajetória histórica, desafios atuais e propostas. São Paulo: Senac, 2003.

Sites consultados

\section{Austrália}

http: / / www.aqf.edu.au/aboutaqf.htm\#whatis

http: / / www.ncver.edu.au/ teaching/31029.html

\section{Brasil}

http://www.mte.gov.br/pnq/proposta_governamental.pdf

\section{Canadá}

http: / / www.inforoutefpt.org

\section{Coreia}

http: / / eng.kedi.re.kr/01_about/message.php

http: / / www.oecd.org/korea

http: / / english.keris.or.kr/es_main/index.jsp

http: / / www.edunet4u.net/main/ english/introduction.jsp

\section{Conselho Europeu}

http: / / europa.eu / legislation_summaries / education_training_youth/general_framework/c10241_pt.htm

\section{Portugal}

www.min-edu.pt

www.inofor.pt 


\section{Vocational training in an international comparative perspective and their repercussions for Brazil \\ Abstract}

This article aims at bringing out a few elements to contribute to the debate on Vocational and Technological Education in Brazil, based on experiences of a few countries which have gone through the process of reform of their systems, all in an international comparative view. In this sense, the context is made explicit, their main basic concepts are discussed, their central elements identified and their repercussions in Brazil are observed. The cases of Australia, Canada, South Corea and Portugal are brought into focus to enlighten the debate. However, it is considered that the elements analyzed may serve as a contribution to the debate of the theme, comparing the public policies studied with those referring to the Brazilian reality. Keywords: Vocational training. Comparative education. Vocational and technological educational reform.

\section{La formation professionnelle dans une perspective internationale comparée et ses répercussions au Brésil Résumé}

Cet article vise apporter quelques éléments comme contribution au débat sur l'Éducation Professionnelle et Technologique au Brésil, ayant comme base une réflexion sur les expériences de quelques pays qui ont passé par un processus de réforme de ses systèmes, le tout dans une vision comparée internationale. Dans ce sens, l'on cherche à expliciter son contexte, discuter ses principaux concepts de base, identifier ses éléments centraux et observer ses répercussions au Brésil. Les cas de l'Australie, Canada, Corée du Sud et Portugal sont avancés pour illuminer le débat. Cependant, l'on juge que les éléments analysés puissent servir comme contribution au débat du thème en discussion, comparant les politiques publiques étudiées avec celles se référant à la réalité brésilienne. Mots clefs: Formation professionnelle. Éducation comparée. Réforme de l'éducation professionnelle et technologique.

\section{Educación profesional en una perspectiva internacional comparada y sus repercusiones en Brasil \\ Resumen}

Este artículo tiene como objetivo traer algunos elementos como contribución al debate sobre la educación profesional y tecnológica en Brasil, teniendo por base la reflexión, en una visión internacional comparada, sobre las experiencias de algunos países, que pasaron por un proceso de reforma de sus sistemas. En ese sentido, se intenta explicitar su contexto, discutir sus principales conceptos embasadores, identificar sus elementos centrales y observar sus repercusiones en Brasil. Los casos de Australia, Canadá, Corea del Sur y Portugal son traídos para iluminar el debate del tema hoy, cotejando las políticas públicas estudiadas con aquellas referentes a la realidad brasileña. Palabras clave: Formación profesional. Educación comparada. Reforma de la educación profesional y tecnológica.

Recebida 1a versão em: 01.06.2009

Aceita 3a versão em: 24.06.2010 